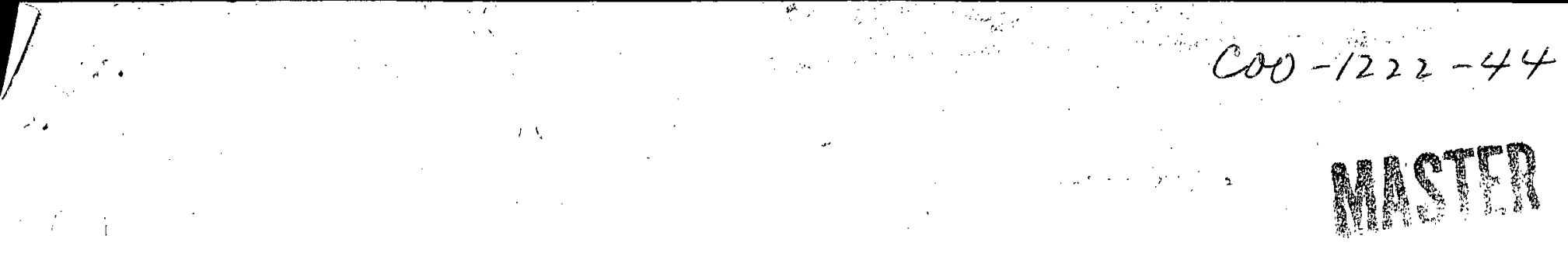

\title{
Computer-Controlled Gas Chromatograph Capable of "Real-Time" \\ Readout of High-Precision Data
}

by

R. S. Swingle and L. B. Rogers

Depertment of Chemistry

Purdue University

Lafayette, Indiana 47907

\section{LEGAL NOTICE}

This report was prepared as an account of work sponsored by the United States Government. Neither sponsored States nor the United States Atomic Energy the United States nor the their employees, nor any of Commission, nor any of their employes, employees, their contractors, subcontractors, or the or assumes any makes any warranty, express or implied, or assumes any legal liability or responsibility for the accuracy, corat pleteness or usefulness of any in epresents that its use product or process disclosed, or represel rights. 


\section{DISCLAIMER}

This report was prepared as an account of work sponsored by an agency of the United States Government. Neither the United States Government nor any agency Thereof, nor any of their employees, makes any warranty, express or implied, or assumes any legal liability or responsibility for the accuracy, completeness, or usefulness of any information, apparatus, product, or process disclosed, or represents that its use would not infringe privately owned rights. Reference herein to any specific commercial product, process, or service by trade name, trademark, manufacturer, or otherwise does not necessarily constitute or imply its endorsement, recommendation, or favoring by the United States Government or any agency thereof. The views and opinions of authors expressed herein do not necessarily state or reflect those of the United States Government or any agency thereof. 


\section{DISCLAIMER}

Portions of this document may be illegible in electronic image products. Images are produced from the best available original document. 
Brief

A combination of hardware and software permits computer control of temperature and flow, monitoring of column inlet pressure and mass flow rate, and calculation of precise retention volumes in real-time.

\section{Abstract}

A gas chromatograph has been assembled which provides computer control of sample injection, column temperature, and flow rate, plus direct computer readout of inlet pressure, mas's flow rate, and detector response. Data processing yields, in real-time, a standard deviation of less than $0.05 \%$ in retention time, which is comparable to previous results obtained using an off-line computer. However, corrected retention volumes determined in real-time had a standard deviation of about $0.4 \%$ which reflected primarily the uncertainty in flow measurement. 


\section{Introduction}

Two high-precision gas chromatographs, capable of $\pm 0.02 \%$ retention-time precision, have been reported in the literature $(1,2)$, and their utility has been well demonstrated (3-7). However, both of those instruments are limited by the fact that the highprecision results must be calculated using an off-line digital computer. Even the chromatograph described by Burke and Thurman (2), - which uses a small dedicated computer for data acquisition, gives an on-line precision of only $\pm 100 \mathrm{msec}$ in the retention time. For high-precision work, those authors dump the raw data onto paper tape and perform further calculations on a larger computer. That requirement can often lead to long turn-around times and the nuisance of processing large amounts of paper tape.

In non-routine applications and in cases where optimization of parameters is required, computer control of experimental variables is often desirable (8-11). In those cases, on-line capability for highprecision readout must be available since the ability of the computer to control the course of study depends upon how well it can evaluate the results from each experiment. Obviously, if the computer lacks the programming and/or the core-space to evaluate input with sufficient precision, uncertainties in the values for the parameters being optimized will be greater than necessary, and much of the overall capability of the system will be wasted.

To meet those objections, a high-precision chromatograph has been interfaced to a small digital computer. $\Lambda$ t the same time, software has been developed which permits precise peak-characteristics to be calculated in real time and typed out within a few seconds after completion of a chromatogram. Hardware has been provided for 
computer control of temperature and flow, and for direct readout of column-inlet pressure and mass flow rate. The latter permits determination of corrected flow rates at the column outlet, and, hence, calculation of precise retention volumes during the course of each chromatographic run. Because of these features, the instrument is easily used for rapid, precise determination of thermodynamic data, quantitation of peak shapes, and accurate qualitative identification of unknown peaks.

\section{System Design}

Gas Chromatograph: A block diagram of the gas chromatograph and its associated equipment is shown in Figure 1 . The column oven, temperature controller, and temperature-measuring apparatus were essentially identical to those described by Oberholtzer and Rogers (1). Helium carrier gas was purified by passing it through a quartz diffusion cell, Model SLMI (Electron Technology Inc, Kearny, N.J.), fitted with a high-pressure outlet head. The 80 psig supplied from the tank regulator on that head was reduced. to 50 psig by a Millaflow 2-stage pressure regulator (Millaflow Division, National Welding Co., Richmond, California), and passed to a Brooks Model 8744 stainless steel flow controller (Brooks Instrument Division, Emerson Electric Co., Hatfield, Pa.). When operating the gas chromatograph under computer control in the automated mode, the flow controller was replaced by a Brooks Model 8504 ELF, NRS, stainless steel needle-valve'with digital handle. A Hastings-Raydist Model LF-50 mass flow transducer (Hastings-Raydist, Inc., Hampton, Virginia) and a Barocel type 538-i9 differential pressure 
sensor (Datametrics, Inc., Waltham, Mass.) were placed downstream from the flow controller. One side of the differential pressure sensor was vented to the atmosphere through tro meters of 0.32 cm i.d. tubing. All the above equipment, with the exception of the diffusion cell, was housed in a thermostatted box, held at $36.0 \pm 0.1{ }^{\circ} \mathrm{C}$.

Samples were injected into the carrier gas using a pneumatically operated Carle Model 2018 gas sampling valve (Carle Instruments Inc., Fullerton, 'California) or a seiscor Model VIII high-' temperature liquid sampling valve (Seismograph Corporation, Tulsa, Oklahoma). The Carle valve was mounted directly on the ' front of the column oven while the seiscor was placed in the oven itself. Each valve was connected to the column by approximately $15 \mathrm{~cm}$ of $0.058 \mathrm{~cm}$ i.d. capillary tubing.

A Varian 1800-series flame ionization detector (Varian Aeorgraph, Walnut Creek, Calif.) was modified for low dead-volume using a $7.2 \mathrm{~cm}$ length of $0.55 \mathrm{~cm} 0 . \mathrm{d} . \mathrm{X} 0.116 \mathrm{~cm} \mathrm{i.d.} \mathrm{stainless} \mathrm{steel}$ tubing secured to the F.I.D. inlet with a Swagelok nut. About $0.9 \mathrm{~cm}$ of the $7.2 \mathrm{~cm}$ length of tubing was turned down slightly on a lathe to allow the hydrogen to sweep over the end of the tubing and carry the sample to the flame. A $10 \mathrm{~cm}$ length of $0.058 \mathrm{~cm}$ i.d. capillary tubing was silver-soldered to the 0.55 o.d. tubing and extended directly into the oven of the chromatograph. This modified FID was insulated with glass wool and heated with nichrome wire: The polarizing voltage for the detector was supplied from a solid-state Computer Products Model PM538 170-V power supply (Computer Products Component Division, Fort Lauderdale, Florida). To help damp high-frequency vibration, the remote head of a 
high-speed Keithley 417 picoammeter (Keithley Instruments, Cleveland, Ohio) was mounted together with the FID on a special rack that rested on rubber cups. Picoammeter input capacitance was minimized by connecting the FID directly to the remote head with a $4.2 \mathrm{~cm}$ section of low-noise cable. Thus, full-scale response times of about $100 \mathrm{msec}$ at $10^{-11}$ amperes and above vere possible.

Interface and Computer Hardware: A Hewlett-Packard Model 2l15A computer, (Hewlett-Packard, Palo Alto, Calif.) equipped with an 8192-word core nemory, an extended arithmetic unit, a teleprinter, and a high-speed paper-tape reader was used for data acquisition, processing, and control operations. Program assembly and/or compilation was done using a Hewlett-Packard 2il6A computer with 8192-word core memory, teleprinter, high-speed paper-tape reader, high-speed paper-tape punch, and a lodel 2020 magnetic tape unit:

Analog-to-digital conversion was accomplished in part with a Hewlett-Packard Model 2212A voltage-to-frequency converter, which provided an output frequency of $100 \mathrm{KHz}$ for full-scale inputs of $1.0,0.1$ or 0.01 volts. The prerise timing used in data acquisition. was achieved using a DEC Model B405 10MHz crystal clock (Di'gital Equipment Corporation, Maynard, Mass.). Software-programmable decades from $100 \mathrm{KHz}$ to $0.01 \mathrm{~Hz}$ as well as options for dividing an interval by 2 or 5 were available (12). All interface logic was constructed using DEC R-, W- and A-series logic cards.

Two Model HDUM-125-16-10 bi-directional stepping motors with Mode 1 14DUM-A-K81 stepping motor drivers (United Shoe Machinery, Harmonic Drive Division, Beverly, Mass.) were used for computer 
control of oven (column) temperature and flow rate. The steppingmotor resolution vas 2000 steps per revolution, while the stepping rate was variable up to 3000 steps per second. Computer control of column temperature was achieved through attachment of one steppingmotor shaft to $10 \mathrm{~K}$ - and 200-ohm Model 7222, double-shafted Helipot potentiometers (Helipot Division, Beckman Instrument Inc., Fullerton, Calif.) mounted in tandem. The 200-ohm potentiometer was wired to the programmer input of a Melabs temperature controller, permitting computer control over a range of approximately $100 \mathrm{C}^{\circ}$ above the Melabs set-point. Computer control of column flow rate was achieved by having the second motor turn, in tandem, a $10 \mathrm{~K}$-ohm potentiometer as above, and the non-rising stem of the Brooks. needle valve mentioned previously. In both temperature and flow, arrangements, the $10 \mathrm{~K}$-potentiometers were used with mercury cells to determine relative motor position. Both assemblies were mounted on flat aluminum, tooling plate with shaft alignments machined to $0.0025 \mathrm{~cm}$. tolerance. Zero bácklash flexible couplings (Pic Engineering, New York, New York) were used for all shaft connections.

A schematic diagram of the signal-conditioning operational amplifiers is shown in Figure 2. To reduce noise pickup, the analog, signals from the chromatograph were amplified to a nominal $10 \mathrm{~V}$ full scale. The type 1014A Datametrics Electronic Manometer, used in conjunction with the Barocel differential-pressure sensor, supplied $10 \mathrm{~V}$ full scale with no modification. An attenuator switch on the manometer provided full-scale output for ranges from 100 to 0.1 psid. 
The Keithley picoammeter supplied $3 \mathrm{~V}$ full scale for its current ranges. The output was amplified four fold using an Analog Devices Model 232J chopper-stabilized operational amplifier (Ánalog Devices Inc., Cambridge, Mass.). The $12 \mathrm{~V}$ full scale took advantage of the $150 \%$ linear overrange capability of the voltage-to-frequency converter. A separate operational amplifier was used to drive the analog display, usually a recorder, and provided signal isolation from any back emf generated by the display.

The Hastings mass flowmeter used with the flow transducer provided only $2 \mathrm{mV}$ for a $50 \mathrm{ml} / \mathrm{min}$. mass flow rate. Furthermore, although the flowmeter output was pressure independent, it did have superimposed on it a $100 \mathrm{mV}$ peak to peak $10 \mathrm{KHz}$ ac'signal from the bridge excitation source. Thus, while that signal was adequate for operation with a $m V$ recorder, operation with a digital data-acquisition system required additional circuitry. The circuit shown in Figure 2, used Analog Devices components and. effectively filtered out the carrier wave and amplified the $2 \mathrm{mV}$ de signal to io $\mathrm{V}$. It should be noted that while that circuit was relatively slow, the flow transducer itself had about a 15-sec full-scale-response time for, a step-change of $0-30 \mathrm{ml} / \mathrm{min}$ of helium. Furthermore, most gas chromatographic systems require at least 30 seconds to equilibrate after a change in flow rate. Only in fast pressure programing studies would a slow response lead to difficulties, and in those cases perhaps the flowmeter designed by Thurman and Burke (13) would be more suitable. Unfortunately, those authors gave no response times and said only that the flowmeter response was "fast". 
All resistors in the above circuits were $1 \%, 5 \mathrm{ppm} / \mathrm{C}^{\circ}$ wirewound precision resistors (Precision Resistor Co., Hillside, N.J.). The analog circuitry was housed in a $36.0 \pm 0.1{ }^{\circ} \mathrm{C}$ thermostatted box.

Figure 2 also shows the interface logic. The logic symbols are those used in Reference 14. The analog signals were multiplexed through DEC A-111 guarded-relay multiplexer switches to a 10:1 voltage divider located at the $1-V$ input of the voltage-tofrequency converter (VFC). The pulse train from the VFC nassed through a modified DEC W-510 level converter to achieve 0 and $-3 \mathrm{~V}$ logic levels. A NAND gate, when enabled, passed the pulse train to a 16-bit binary counting register. Upon execution of the appropriate computer commands, the contents of this register were transferred through the $W-60 I$ level converters into the duplex register card and into the accumulator of the computer.

Table I summarizes the output control functions and their corresponding octal codes. Computer control of the stepping motors, valves, multiplexer, and interface itself was accomplished using output bits $0-11$ of the duplex register card. The output of each of those Dits passed through a modified. W-510 level converter whose output; in turn, toggled a J-K flip-flop. The flipflops served as temporary output-storage buffers, so that different output operations could be accomplished independently during the same time period. For example, if the multiplexer was being held in a given state, the binary register could be cleared without clearing the multiplexer or without including the multiplexer control code in the, register-clearing output code. As will be seen later, this buffer greatly facilitated the control programming. 
Figure 2 shows the, output functions for all 12 bits. Bits 0-2 were used to actuate valve-drive circuitry discussed previously (15). Bits 0 and 6 were gated together and conbined with a pulse amplifier for diréct clearing of all output bits. Bits 1 and 2 performed the same clearing operation on the binary counting register, but in that case, the pulse amplifier was jumpered to provide a $400 \mathrm{msec}$ pulse and prevent "carries" in the counting register. Remote actuation of the stepping-motor drivers required a negativegoing pulse of at least $10 \mathrm{~V}$ magnitude, I usec fall-time, and 20 usec duration. The gating illustrated satisfied those requirements and, for example, when bits 3 and 5 were set, stepping motor number one took a step in the counter-clockwise direction. Bits 7-10 controlled the multiplexer. Bit li controlled the binary-register gate and the flag bit. When the gate was disabled, the one-shot provided a.I usec delay to allow complete settling of the counting register before setting the flag and strobing the contents of the counting register into the computer.

Software: To facilitate the development of original programs for this gas chromatograph, an assembly-language relocatable subroutine library was compiled. Subroutines in the library are first, second, and third order, and for the most part, perform specific functions related to the hardware described above. For example, a simple "CALI REGCL" instruction, results' in a direct clear operation being performed on the binary counting register. A list of the subroutine names along with a short description of the purpose of each is shown in Table II. The routines grouped together at the bottom of the table are used in the programs described 


$$
-10-
$$

below so as to permit data acquisition under interrupt control, and pseudo "real-time" data processing. A system of common buffers is used for temporary storage of integer data points. Those data are then floated and transferred to a working buffer in blocks of fifty, replacing date that heve been processed. $\therefore$

A general-pupose program, GOUTl, was written in HewlettPackard Fortran for use in operating the chromatograph in a semi-automated mode. Data are taken under interrupt control and processed in, essentially, real-time. A Savitsky and Golay (16) eleven-point quadratic derivative smooth is used in conjunction with consistency tests to detect peaks. Peak area is determined by summing the data points from the beginning to the end of the peak. A linear least-squares fit to about 100 data points both before and after each peak is applied for area correction. Less than 100 points are used if the program detects an absolute value of the baseline derivative that exceeds a specified slope

The retention time of the peak mean, $t$, is defined by the first moment of the peak $(17-18)$. The peak variance, $V$ is found by calculating the second moment about the mean and is further related to the number of theoretical plates by the equation

$$
N=\frac{(t)^{2}}{\underline{V}}
$$

Program GOUTI makes no provision for overlapped peaks other than to dron a perpendicular to the baseline if the second peak is detected. below a thresknld of 1.2 times the baseline. 


\section{$-11-$}

The operation of GOUTI is best described by looking at the input and output show in Figure 3. The initial pause permits the experimenter to enter any "passive" parameters such as name, date, runidentification number, etc. using the teletype "local" mode. Upon pushing run, the experimenter is prompted to enter the following active parameters. SCLI and SCL2 are the picoammeter attenuation and range settings, respectively, used for calculation of peak area in microcoulombs. TAMB is the ambient temperature, and TOVN the oven (column) temperature. PBAR is the barometric pressure, to the nearest $0.1 \mathrm{~mm}$, and is assumed to be the column-outlet pressure. TRIG is the derivative trigger value used for peak detection. PKMIN is the minimum area a peak must have before GOUTI will recognize it, and KPTCH is the number of points at the beginning of a run which the experimenter does not wish to have processed. This last parameter is necessary because sample injection using an automated sampling valve sometimes gives an uneven baseline at the beginning of a chromatogram which can be interpreted by GOUTl as a peak. Finally, the experimenter is prompted for the dataacquisition rate, in points per second. After all manual input has "been completed, the program samples the mass flow rate and the column-inlet pressure, and then halts so as to permit any lastminute adjustments, should they be necessary.

Upon pushing "Run", the sample is injected and data acquisition and processing begin. After the experimenter is satisfied that the chromatogram has been completed, he sets bit 1 of the switch register up. GOUTI terminates data acquisition, finishes processing the resident data, and prints on the teletype for each peak detected the peak number, area in counts, area in microcoulombs, 
corrected retention time, corrected retention volume and negative logarithm of the area. The outlet flow rate in $\mathrm{ml} / \mathrm{min}$ corrected for column pressure-drop and temperature, and the James and Martin gas-compressibility coefficient, $\underline{j}$, are then printed, foilowed by the peak number, variance, number of plates, plates-per-second, and height equivalent to a theoretical plate for each peak in the chromatogram. The program then cycles back to its beginning and again pauses. Should a second run be desired, the experimenter may elect to enter a new set of active parameters, or may set bit 15 up and bypass the input stage of the program. In that case, GOUTl assumes the active parameters to be the same as before, and it proceeds to ask for a new data-rate.

A second Fortran program, OPCON, operates the gas chromatograph in its most highly automated mode. As such, OPCON incorporates essentially all of GOUTl plus the programming necessary for computer control of the column temperature and flow rate. A simplified flow chart is show in Figure 4. Because OPCON is being used in resolution studies, it is presently set up only for two-component mixtures. It could, however, be changed easily to accomodate any reasonable number of components.

In using OPCON, the operator sets up the initial experimental conditions at the lowest flow rate and column temperature to be run. OPCON, prompts the experimenter for various control parameters in addition to the input for GoUTl described above. These include the number of temperatures to be run, not to exceed seven; the number of steps between adjacent temperatures; the number of flow rates to be run at each temperature, not to exceed seven; 
the number of steps between adjacent flow rates; the number of replicates to be run at each set of experimental conditions; the maximum run time per chromatogram; the delay, in minutes, between changing the flow and injtiating the next run; the delay, in minutes between changing the temperature and initiating the next run; the total maximum number of steps allowed for increasing the temperature, not to exceed 19,500; the total maximum number of steps allowed for increasing the flow, not to exceed 19,500; and the slope of the calibration curve for number of steps vs temperature. The operator is then prompted for the data-acquisition rate, and, after it has been entered, OPCON begins execution.

The flow rate is sampled by the computer at two-second intervals until the flow rate calculated from two successive readings differs Iess than $0.5 \%$. The column-inlet pressure is then read in a similar manner until the if factor varies less than $0.05 \%$ for two successive readings. If the flow is equilibrated, both parameters are fixed in less than 10 seconds. The sample is injected and data acquisition begins. The computer continues to acquire and process data until either two peaks have been eluted or the maximum run-time has been exceeded, following which the data for each peals are dumped on the teletype. OPCON then decides whether all replicates at all experimental conditions have been run as specified in the control input. If they have not, the program makes the decision as to what changes, if any, in the experimental conditions are appropriate, makes those changes, waits for system equilibration, and returns to read the flow. rate, etc. 
Changes in flow rate are made in a pseudo-random order. Likewise, after all desired flow rates have been run at a given temperature, the temperatures are varied in a Fseudo-random fashion.

The OPCON output for each chromatogram contains the same information about each peak as described previously for GOUTl. In addition to the outlet flow rate and $\underline{j}$ factor, OPCON writes the oven temperature in ${ }^{\circ}$, calculated from a calibration curve that will be described below, the resolution between the two peaks calculated from

$$
\underline{R}_{S}=\frac{\left(t_{2}-t_{1}\right)}{2\left(\sigma_{2}+\sigma_{1}\right)}
$$

and a pressure correction factor, $f_{-1}$ (18) calculated from

$$
f_{1}=\frac{9\left(p^{4}-1\right)\left(p^{2}-1\right)}{.8\left(p^{3}-1\right)^{2}}
$$

where $\underline{P}$ is the inlet-to-outlet pressure ratio.

Á simple assembly-language program, TANDR, was written for use in calibration of flow rate, inlet pressure, and stepping-motor settings. The program aquires a number of data points at a given rate from one multiplexer channel, and then dumps the individual points and their average on the teletype. Both the data-acquisition rate and the number of points are specified by the experimenter. It should be noted that the data-acquisition rate must be the same as that used under normal operating conditions to insure identical integration times for all data. 
Calibration: The'digitized output of the mass flowmeter was calibrated against a soap-film bubblemeter. Those resũlts are shown in Figure 5. The different symbols indicate data taken on different days. Each point represents the average of 600 readings taken at 10 points/sec. The short-term fluctuations over an approximate 1-to 2 -min period were found to be less than $0.1 \%$. First- through fourth-order polynomial equations were least-squares fitted to the data and, as expected from the slightly s-shaped curve, a cubic equation was found to be satisfactory. The standard deviation, of the points from the fitted line was $0.095 \mathrm{ml} / \mathrm{min}$, over a range of 3 to $48 \mathrm{ml} / \mathrm{min}$, or about $0.2 \%$ of full scale. This was the best that could reasonably be expected from the system because the Brooks flow controller was rated at $0.3 \%$ stability. Furthermore, $0.2 \%$ of the $2 \mathrm{mV}$ output of the mass flowmeter corresponded to measurements of voltage differences in the $u V$ range. Because the accuracy of the measurement depended upon proper zeroing of the operational amplifier circuit, and because an accuracy of $0.1 \mathrm{ml} / \mathrm{min}$ was desired (and attained), temperature thermostatting of all of the apparatus for controlling and measuring the flow was necessary. The flowmeter output was observed to be independent of pressure over a 1 to 50 psid range.

The 30 psid range of the Datametrics electronic manometer was calibrated against a Heise Model C, 75 psig, bourdon-tube gauge (Heise Bourdon Tube Co., Inc., Newtown, Connecticut). The data are shom in Figure 6 with different symbols, again, denoting data taken on different days. Short-term variations in the manometer output were less than $0.01 \%$. A linear least-squares fit to the data gave a 
standard deviation of $0.004 \%$ over the range from 3 to 30 psid. This was not surprising considering the rated specification of $\pm .01 \%$ accuracy. In this case, the pressure manometer output itself was more reliable than the technique used for calibration. As indicated earlier, pressure ranges other than 30 psid were available, but inlet pressures above 30 psid have not been encountered in our study.

Whenever the computer made a change in column temperature, the new temperature vas calculated from the calibration curve show in Figure 7 in which the temperature in $C^{\circ}$ is plotted against the number of steps the stepping motor has turned a 200-ohm potentiometer wired to the temperature controller. The linear equation that was least-squares fitted to those data gave a standar deviation of $\pm 0.25^{\circ} \mathrm{C}$. The slope of the line was independent of the initial setpoint of the temperature controller, as expected, since a platinum sensing element was used. The programming range of $100 \mathrm{C}^{\circ}$ provided by the 200-ohm potentiometer could be increased to $300 \mathrm{C}^{\circ}$ by substituting a 500-ohm model, which would also change the slope of the calibration curve.

Chemicals: The chromatographic column was a $100 \mathrm{~cm} \times 0.32 \mathrm{~cm}$ i.d. stainless steel tube packed with $5 \%$ OV-I on 80/100-mesh Chromosorb G. A sample stream consisting of a binary mixture of n-pentane and $\underline{n}$-hexane (Matheson Coleman \& Bell, Chromotoquality Grade) was prepared in the following maniner. Fach of two glass gas-saturation assemblies was half-filled with one of the hydrocarbons, and placed in separate water baths. Each water bath was thermostatted at a different temperature to $\pm 0.1 \mathrm{C}^{0}$ with a Sargent Model S-W temperature controller (E. H. Sargent \& Co., Chicago, III.). Two Brooks Model 8743 
flow controllers provided steady streams of high-purity nitrogen (PrePurified Grade, Air Reduction Co.) through each saturator. The streams were then mixed and passed to the sampling valve. By changing the temperatures of the water baths and the flow rates of the nitrogen streams, binary samples of any relative concentration could be produced. Further dilution of the mixture with pure nitrogen permitted changes to be made in the absolute levels of the concentrations. To prevent sample condensation, all connecting tubing between the sampling valve, and the water baths. operated above room temperature, was heated to about $60^{\circ} \mathrm{C}$ using heating tape and was insulated with glass wool and aluminum foil. Similarly, a sample stream of methane (Matheson Co., C.P. Grade) in high-purity nitrogen was prepared in order to determine the void volume of the column.

Results

The peak-sensing portions of programs GOUTI and OPCON were tested by interrupting the program operation at an appropriate point and entering, through the switch register, synthetic data for a baseline and for a normal distribution curve at every 0.1 standard deviation unit. The program was then restarted and the computer output for the synthetic peak compared to hand-calculated values. Agreement within $0.01 \%$ was found for area, mean retention time, and peak variance, thereby indicating that the programs were functioning correctly.

Using the pentane-hexane sample stream, five replicate chromatograms were run at several different sets of experimental conditions. Table III shows the precision found for retention time, variance, 
and HETP for one set. Note that the standard deviations of $\pm 0.02 \%$ for retention time and $\pm 0.04 \%$ for peak variance were comparable to those obtained using an off-line computer (I).' Presumably, higher peak moments could also have been comparable had they been calculated. It should be mentioned that standard deviations for peak characteristics depend a great deal upon the peak shape. Not all peaks could be characterized with the precision reported above.

Table II also gives data for the column-outlet flow rate, corrected for temperature and pressure drop, and the gas compressibility coefficient. Although the $\pm 0.35 \%$ uncertainty in flow rate was expected from the calibration procedures and was comparable to that taken with a soap-film bubblemeter, the present system was considerably faster and more convenient. Programs GOUTI and. OPCON printed only four significant figures of the gas compressibility constant, and, since the measurement was better than that, precision was reported simply as $<0.01 \%$. One further measure of the system reliability can be seen from the retention-volume data for methane which are shown at the bottom of Table III. Note that the data were obtained at two different 'column temperatures, inlet pressures, and $\mathrm{flow}$, rates and that retention volumes agreed within $\pm 0.4 \%$ Because of a long time-constant for equilibration of the sampling system ( $230 \mathrm{~min}$ ), no attempt was made to achieve completely reproducible sample sizes in these runs. Consequently the precision of peak area in Table IV is not representative of the gas chromatograph, but indicates the non-equilibrium in the sampling system. From the results found with the normal curve, it was felt that with a baseline constant to about \pm 2 counts, reproducibility of peak area would always depend upon.sampling and not the chromatograph or the 
peak-detection software.

\section{Discussion}

To date, our primary objective has been to demonstrate that high-precision chromatographic data can be obtained using a small, on-line, digital computer. However, significant extension of the existing software is severely linited by the availability of only $8 \mathrm{~K}$ of core memory. A special compilation procedure, combined with deletion of almost all Holarith output, was necessary to put, OPCON into' $8 \mathrm{~K}$. At present, there are less than 10 uncómmitted core locations. By rewriting some of the programs, a small gain in "free" core would be possible. However, a major increase in core locations is required to include desirable features such as direct computer readouts of column temperature to $\pm 0.01 \mathrm{C}^{\circ}$ and columnoutlet (or barometric) pressure, computer-controlled feedback for each of the major variables, and software capability for modification of experimental design. There is little question that all of the above goals could be accomplished in $8 \mathrm{~K}$ of core by writing all, or nearly all, of the software in assembly language, but the use of a higher-level language was considered to be highly desirable for one-of-a-kind research applications because the programs could be written and debugged in shorter times. For that reason and because the programs could be adapted more easily to other computers, GOUTI and OPCON were written in FORTRAN.

Fortunately, more memory will soon be available on a different computer system. As a result, the two hardware extensions mentioned above will be incorporated in addition to an interface modification. 
That last change will involve the gate between the binary counting register and the $\mathrm{VFC}$, which is controlled directly from the computer. The timing for enabling and disabling this gate was critical in order to obtain meaningful analog-to-digital conversion. This meant that the program had to avoid the chance that the computer might have just started executing a, time consuming uninterruptable instruction. For example, a floating-point divide requires 560 usec, during which up to five "extra" counts could be added to the counting register. For that reason, the progranmable clock was set up to provide ten flags for each data point. The interrupt service routine counted the flags and, after the ninth, disabled the interrupt and waited for the tenth. When it came up, the gate was immediately disabled, thereby preventing any extra pulses from being counted. However, as a result, one tenth of the computer time was lost through waiting. Even so, data rates up to 25 points per second could be handled in real time. Since the new computer system will operate in a time-shared mode among several instruments, the clock will have to be wired directly to the gate in order to free the "Iost" computer time.

Similarly, the availability of more memory will permit desirable software modifications to be included. For example, GOUTl uses an eleven-point first-derivative quadratic smooth for peak detection. That choice vill not always be the best, and it would be beneficial to provide a program option whereby the computer could choose one from a number of such functions, the choice being based upon data-acquisition rate, baseline noise, peak variance, etc. Unsophisticated program deconvolution of overlapping peaks, and the calculation of the third and fourth central moments of each peak 
would also be welcome additions.

- One of the most productive uses of this high-precision gas chromatograph will be in automatic empirical determinations of optimum chromatographic conditions for particular separations. A first step in this direction has been taken by Thurman, Mueller, and Burke (19). Their approach involved, however, only single-. component systems, and a computer programmed to increase the flowrate between successive chromatograms until a minimum was found in the van Deempter plot. Furthermore, no absolute determination of the column-outlet flow rate was possible. To arrive at a better solution , to the optimization problem and, at the same time, to realize the full capabilities of our instrument, a program is being written which wili include a statistical design for locating, in minimum time, the optimum'in a multi-dimensional plot of the parameters to be optimized against resolution per unit time.

At present, optimization studies are being performed, but the decision about how to proceed after each set of runs is made by the operator who then has to enter by teletype new instructions for the next series of runs. Even so, there is a tremendous saving, both in turn-around time between data acquisition and processing, and in operator time.

\section{Acknowledgment}

The authors are indebted to Dr. S. P. Perone for the use of the two computers, provided through the National Science Foundation, and to Dr. J. W. Amy for his many helpful discussions. 
References

1. J. E. Oberholtzer and I. B. Rogers, fnai. Chem., 41, 1234 (1969).

2. M. F. Burke and R. G. Thurman, J. Chromatogr. Sci., 8, 39 (1970)..

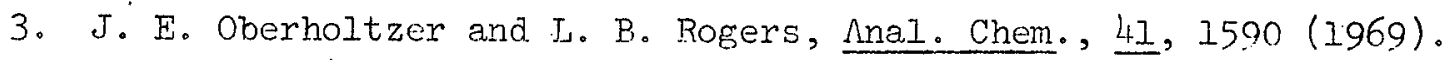

4. A. K. Moreland and L. B. Rogers, Separ. Sci., 6, I (1971).

5. I. J. Lorenz, R. A. Culp and L. B. Rogers, Anal. Chem., 42, 979 (1970).

6. R. A. Culp, C. H. Lochmlller, A. K. Moreland, R. S. Swingle, and L. B. Rogers, J. Chromatogr. Sci., in press.

7. D. Macnaughtan and I. B. Rogers, unpublished data, 1970.

8. S. P. Perone, D. O. Jones and W. F. Gutnecht, Mnal. Chem., 4I, 1154 (1969).

9. G. E. James and H. I. Pardue, ibid., p 1618.

10. I. Ramaley and G. S. Wilson, ibid., 42, 606 (1970).

1l. R. G. Thurman, K. A. Mueller, and M. F. Burke, J. Chromatogr. Sci., in press.

12. S. P. Perone and J.F. Eagleston, J. Chem. Ed., in press.

13. R. G. Thurman and M. F. Burke, J. Chromàtogr. Sci., in press.

14. "Logic Handbook", Digital Equipment Corp., Maynard, Mass., 1968.

15. J. E. Oberholtzer, Anal. Chem. 39, 1627 (1964)。

16: A. Savitzky and M. J. E. Golay, ibid., 36, 1627 (1964).

17. O. Brubner, "Advances in Chromatography", J. C. Giddings and R. A. Keller, Eds., Marcel Dekker, New York, Vol. 6, 1968, pp. 173-209.

18. E. Grushka, M. N. Myers, P.D. Schettler, and J.C. Giddings, Anal. Chem., 41, 889 (1969).

19. J. C. Giddings, S. L. Seager, L. R. Stuki and G. H. Stewart, ibid., 32, 867 (1960).

Supported in part by the U. S. Atomic Energy Commission through Contract $\mathrm{AT}(11-1)-1222$. 
Table 1

Octal Codes For Computer Control of Experiment

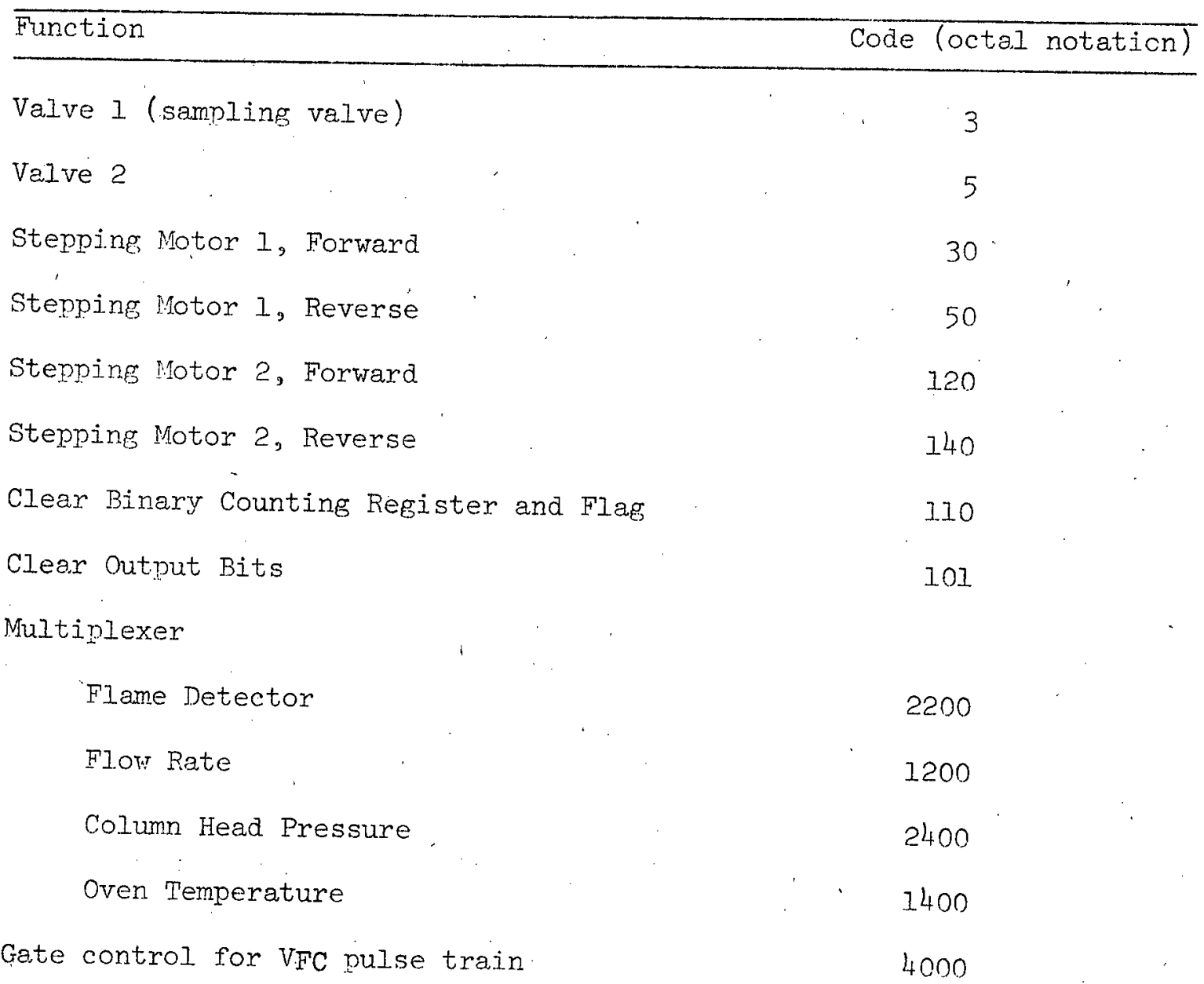


Table II

Subroutine Names and Functions

Name

CLEAR

FLO

PRESS

RATE

REGCI

ISTPF

ISTPR

2STPF

2STPR

STOP 3

VALVE

STRT

GO

CKFIG

SERVE
Functions

Clear output bits

Read mass flowrate

Read inlet pressure

Get data acquisition rate from TTY

Clear 16 bit binary up-counter

Step motor one forward

Step motor one reverse

Step motor two forward

Step motor two reverse

Disable programmable clock

Activate sampling valve

Establish interrupt linkage on data channel

Initialize pointers, and take first 200 data points

Rotate data into working buffer

Service interrunt on data channel 


\section{Table III}

Precision of Chromatographic Data ,

\begin{tabular}{|c|c|c|c|}
\hline Parameter & Units & Value & $\% \operatorname{ReI}$. \\
\hline Flow Rate & $\mathrm{ml} / \mathrm{min}$ & $14.42 \pm 0.05$ & \pm 0.35 \\
\hline j factor & - & $0.6761 \pm 0.001$ & $< \pm 0.01$ \\
\hline Area (n-pentane) & ucoul & $0.02853 \stackrel{\ddagger}{\ddagger} 0.00017$ & \pm 0.61 \\
\hline (n-hexane) & ucoul & $0.03137 \pm 0.00051$ & \pm 1.63 \\
\hline Retention time (n-pentane) & $\sec$ & $9.000 \pm 0.003$ & \pm 0.03 \\
\hline (n-hexane) & $\sec$ & $15.946 \pm 0.003$ & \pm 0.02 \\
\hline Variance (n-pentane) & $\sec ^{2}$ & $0.2265 \pm 0.0001$ & \pm 0.04 \\
\hline (n-hexane) & $\sec ^{2}$ & $0.4002 \pm 0.0004$ & \pm 0.09 \\
\hline HETP ( $\underline{n}$-Pentane) & $\mathrm{mm}$ & $0.642 \pm 0.001$ & \pm 0.16 \\
\hline$($ n-hexane $)$ & $\mathrm{mm}$ & $0.786 \div 0.001$ & \pm 0.13 \\
\hline $\begin{array}{c}\text { Retention volume } \\
\text { (methane) }\end{array}$ & $\mathrm{mI}$ & $2.227^{+}-0.009$ & \pm 0.40 \\
\hline
\end{tabular}




\section{List of Figure Captions}

Figure 1. Block diagram of the instrument.

Figure 2. Schematic diagram of signal conditioning and interfáce electronics.

Figure 3. Teletype input/output for program GOUTI.

Figure 4. Simplified flow chart for program OPCON.

Figure 5. Calibration curve for mass flowmeter.

Li Day one
$\triangle$ Day two
O Day three

Figure 6. Calibration curve for electronic manometer.

$$
\begin{aligned}
& + \text { Day one } \\
& \triangle \text { Day two }
\end{aligned}
$$

Figure 7 . Calibration curve for temperature controlling stepping motor. 

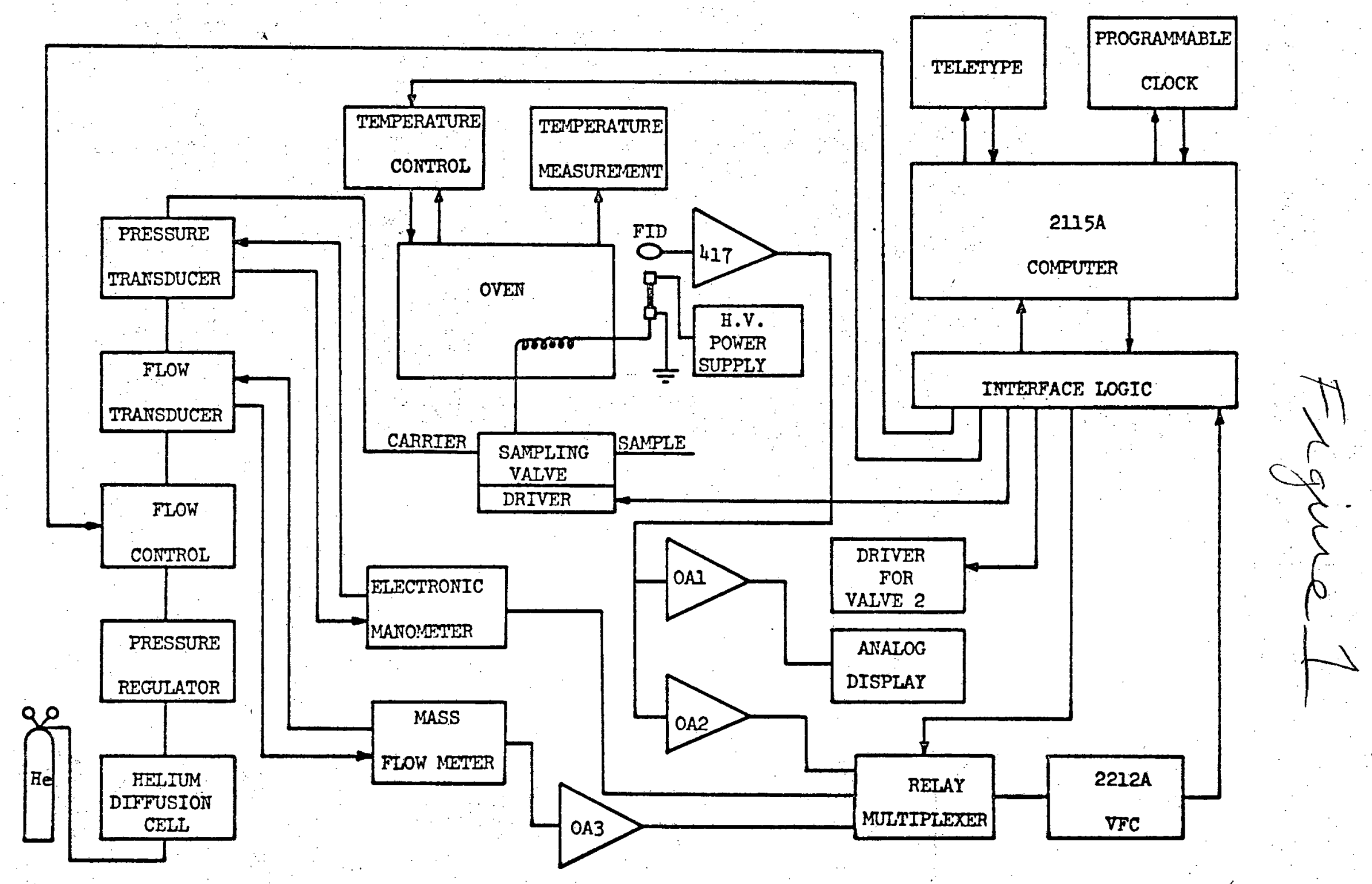


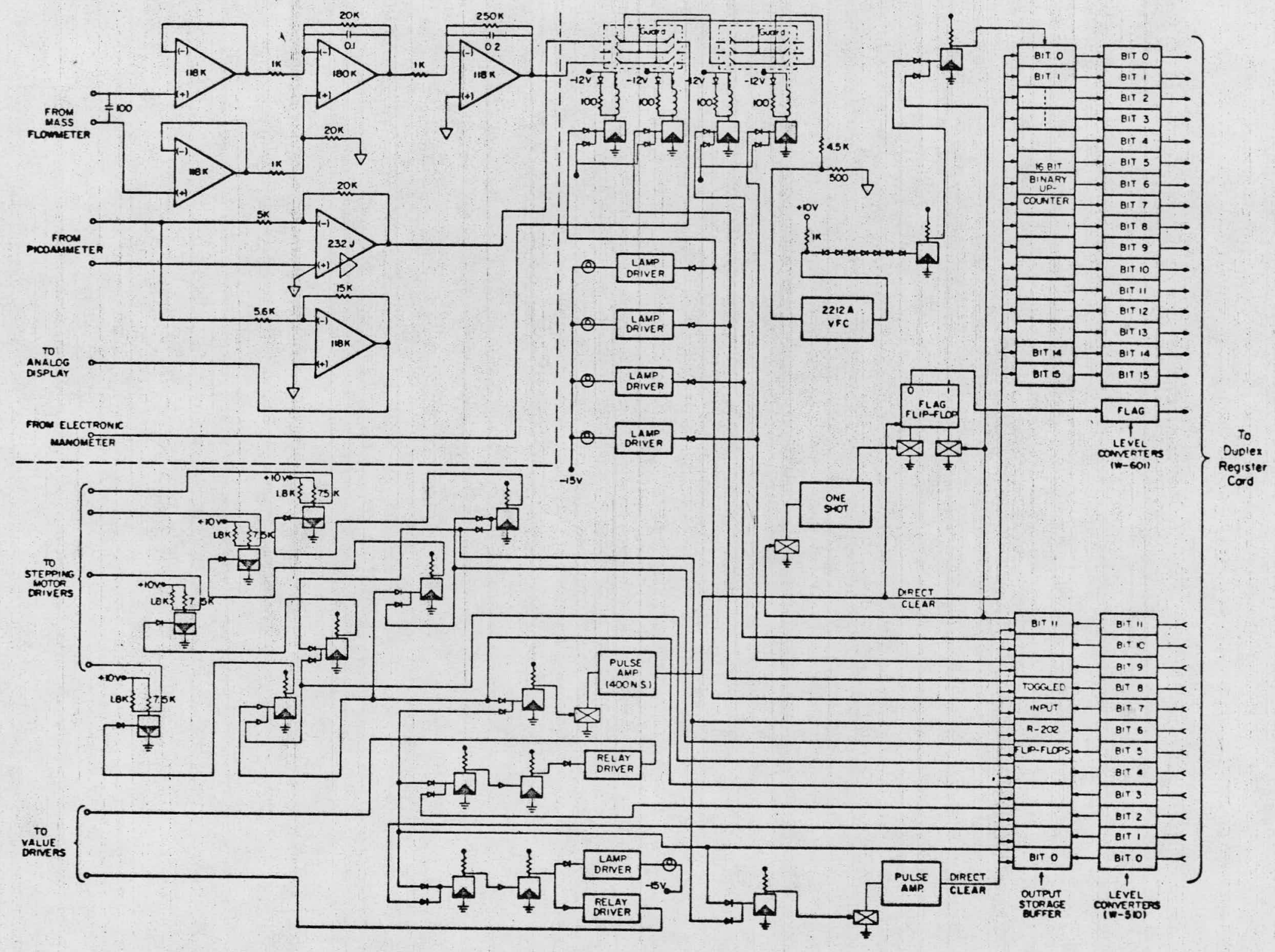


PAUSE

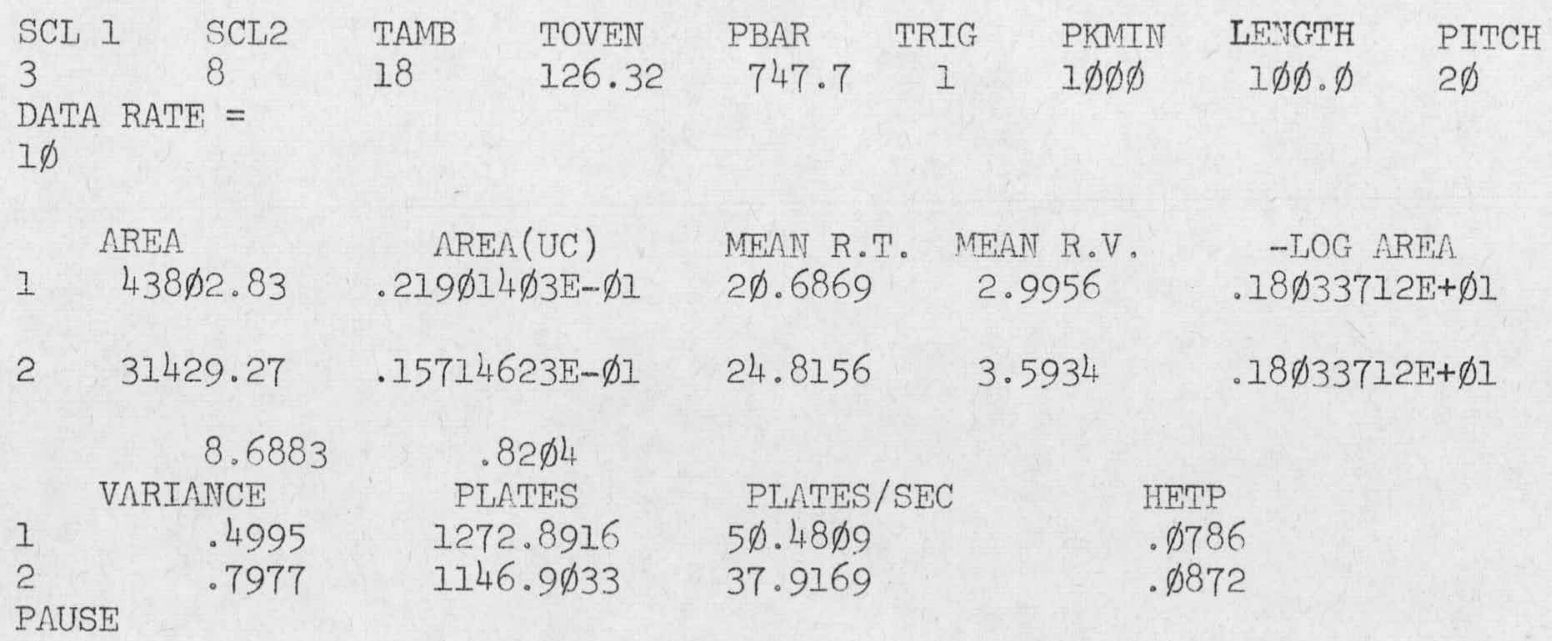




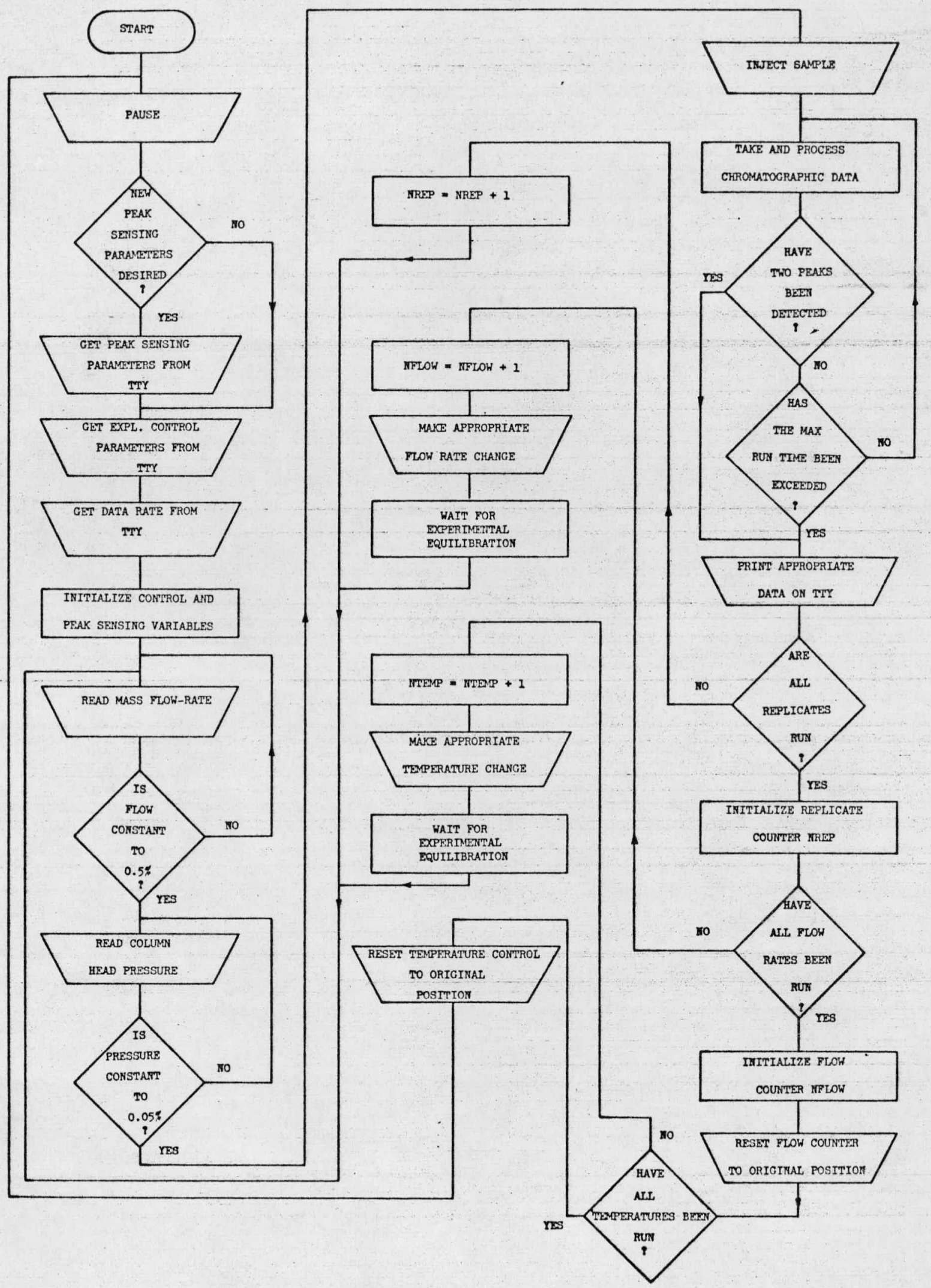




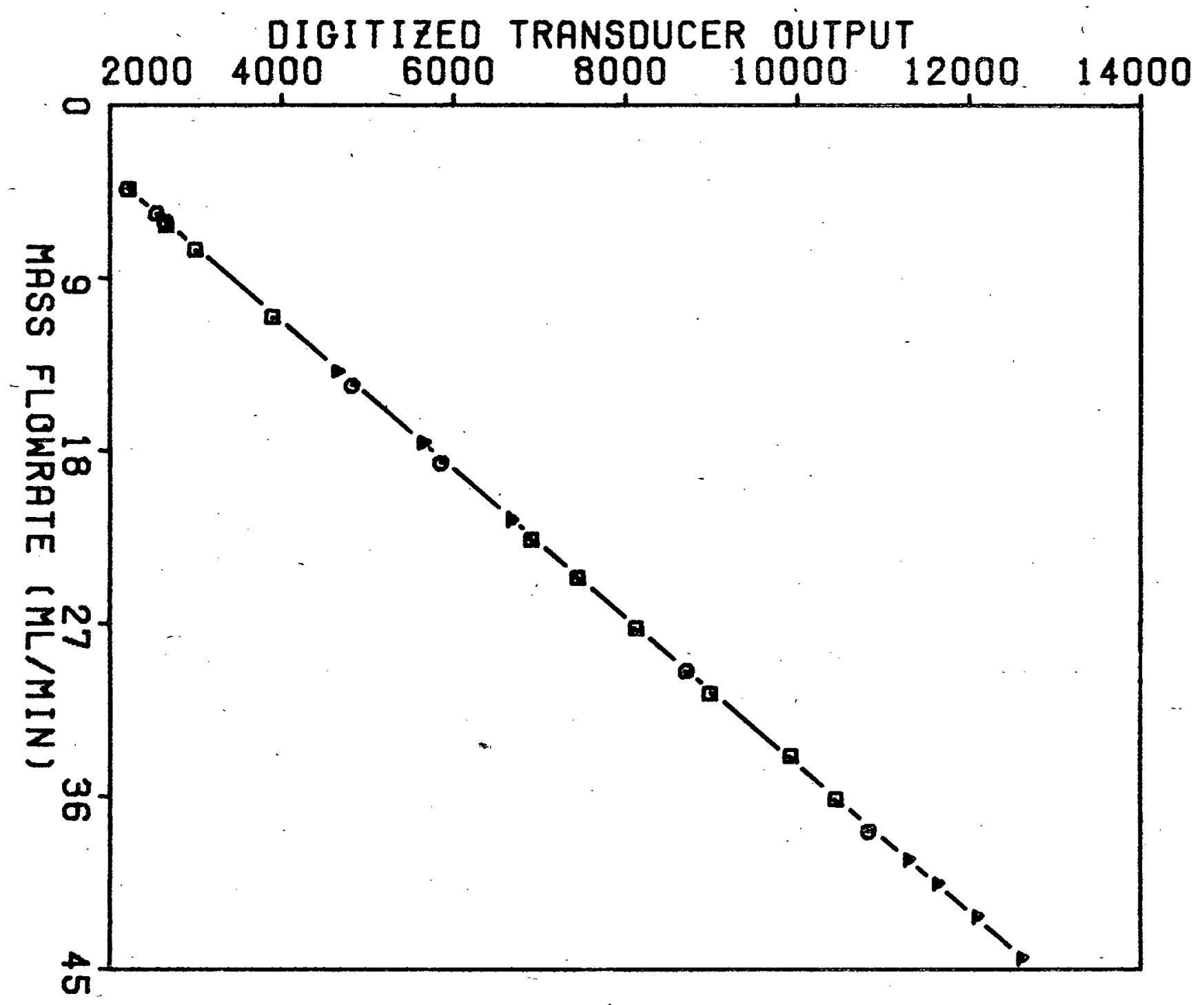




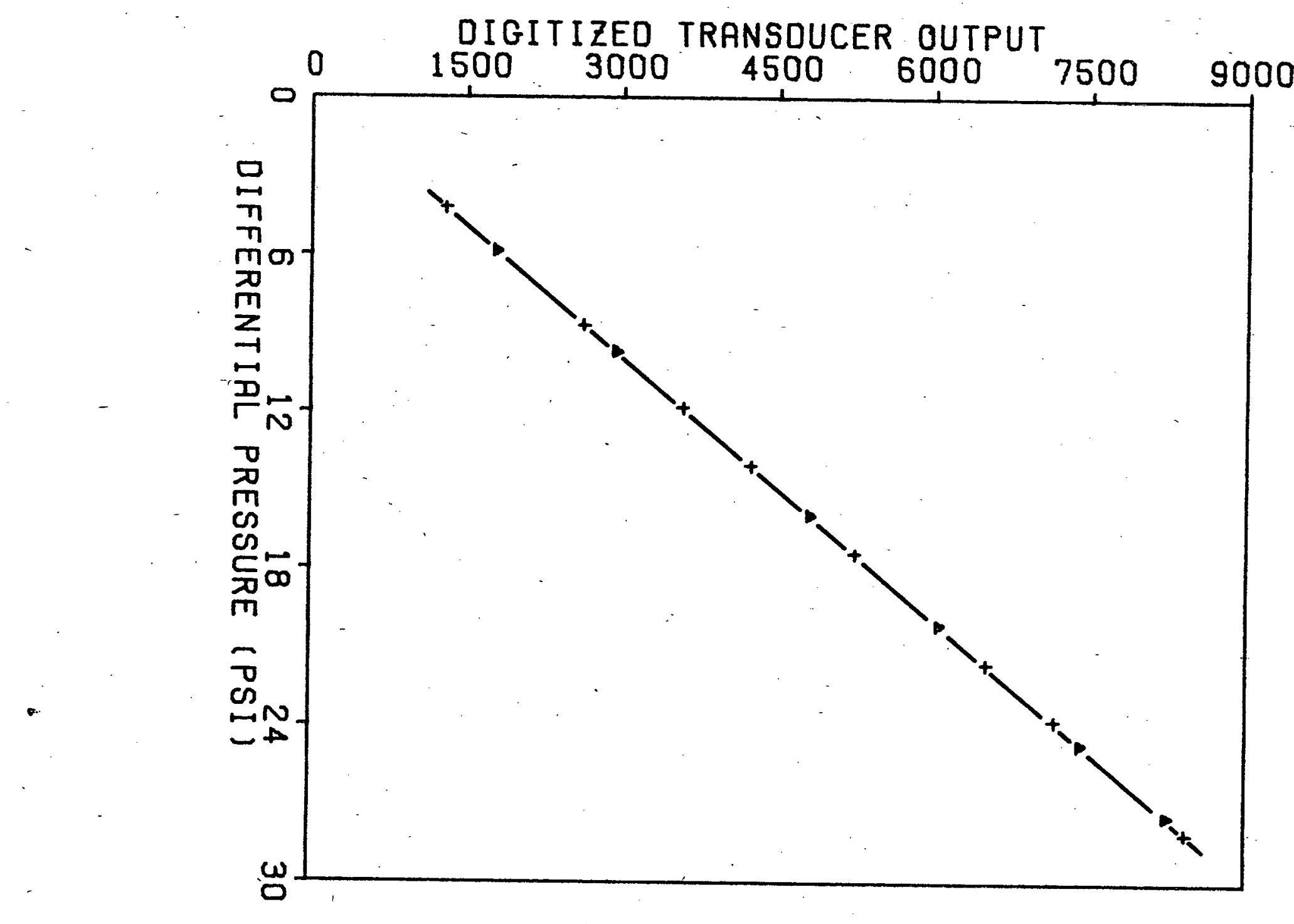




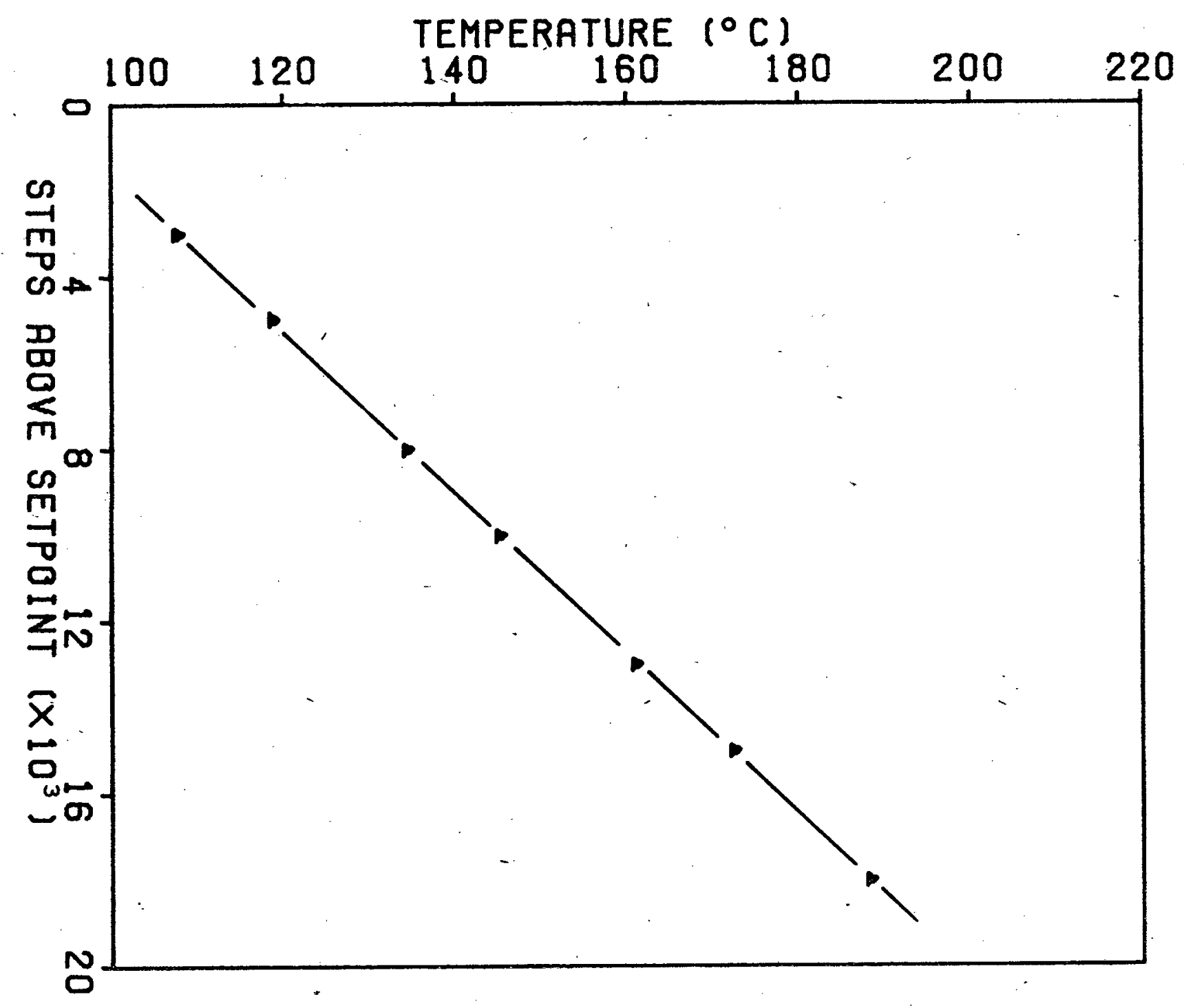

